Bangl. J. Vet. Med. (2006). 4 (2): 93-96

\title{
INVESTIGATION ON BABY CHICK RANIKHET DISEASE VACCINE ADMINISTRATION IN CHICKS OF VACCINATED AND NONVACCINATED ORIGIN
}

\author{
K. Begum, M. S. R. Khan*, M. B. Rahman, M. A. Kafi, M. Das and S. A. A. Mamun
}

Department of Microbiology and Hygiene, Faculty of Veterinary Science, Bangladesh Agricultural University, Mymensingh-2202, Bangladesh

*Corresponding author’s e-mail: msrkhan001@yahoo.com, msrkhan001@gmail.com

\begin{abstract}
Persistence of maternally derived antibody to Baby Chick Ranikhet Disease Vaccine and its influence on vaccination programme in chicks of vaccinated and nonvaccinated origin were determined during the period from July 2005 to May 2006. The study suggested an effective vaccination schedule of Baby Chick Ranikhet Disease Vaccine in chicks of vaccinated and nonvaccinated origin. The optimum age for vaccination of chicks of vaccinated and nonvaccinated origin were determined by inoculating vaccine following two different vaccination schedules. In one schedule chicks of group $\mathrm{C}$ of vaccinated origin and group $\mathrm{F}$ of nonvaccinated origin were vaccinated primarily at day 4 and was boosted at day 19 and in another schedule the chicks of group D of vaccinated origin were vaccinated once at day 14 without giving booster dose. It was found that maternally derived antibody passed over from the parents to progeny chicks and remain protective for the chicks of group A of vaccinated origin until 18 days of age and the chicks of group B of nonvaccinated origin until 5 days of age. This maternally derived antibody was retained particularly up to 24 days and 11 days in chicks of group A and B obtained from parent vaccinated and nonvaccinated flock respectively. Chicks of group C primarily vaccinated with Baby Chick Ranikhet Disease Vaccine revealed slightly positive effect to rise of antibody during their gradual increase of age due to the presence of high level of antibody at the time of primary vaccination where as in chicks of group $\mathrm{F}$ antibody level was increasing impetuously due to the low level of antibody at the time of vaccination. Chicks of group D vaccinated at the state of subsidence of maternally derived antibody with Baby Chick Ranikhet Disease Vaccine showed impetuous production of antibody titers. Chicks possessing high level of maternally derived antibody may be vaccinated singly against Newcastle disease when they are 14 to 18 days old and chicks possessing low level of maternally derived antibody may be vaccinated twice at 4 and 19 days of age.
\end{abstract}

Key words: BCRDV, F-strain NDV, chicks of vaccinated and nonvaccinated origin, MDA, haemagglutination inhibition test

\section{INTRODUCTION}

Newcastle disease (ND) also known as Ranikhet disease (RD) is a highly contagious viral disease that attacks many species of domestic and wild birds (Garib et al., 2003). The disease is caused by single stranded RNA virus known as avian paramyxovirus belonging to the family paramyxoviridae (Garib et al., 2003) The infection is still appeared in Bangladesh every year in the form of epidemic and appears to have claiming $40-60 \%$ of the total mortality in poultry population creating one of the major problems in the development of poultry industry in Bangladesh (Chowdhury et al., 1982). Two types of vaccines are still used universally for active immunization which included live and inactivated vaccine against Newcastle disease virus (NDV). In Bangladesh, the schedule of NDV vaccination as followed by Directorate of Livestock Services (DLS) includes administration of Baby Chick Ranikhet Disease Vaccine (BCRDV) prepared from live lentogenic F-strain by intraocular inoculation to first week and 21 day old chicks. This BCRDV maintains the immunity level of chicks up to 2 months of age. Therefore, for the maintenance of immunity to ND, it is mandatory to administer the other types of ND vaccine in the subsequent age of chicken. The DLS of Bangladesh is also engaged in manufacturing of Ranikhet Disease Vaccine (RDV) prepared from live mesogenic M- strain of NDV which is being administered intramuscularly at day 60 and are repeated at every 6 months interval. The optimum age of chicks for vaccination is influenced by a variety of factors including persistence of maternally derived antibody 
(MDA) in chicks, invasive capacity of vaccine virus and development of immune mechanism (Allan et al., 1978ab). MDA interferes with the development of active immunity in chicks after vaccination (Keeble and Wade, 1963). The level of passive immunity in chicks has been found to decline progressively from three days of age and respond well to ND vaccination by 18-20 days of age in chicks of vaccinated origin. But chicks of nonvaccinated origin possessed insignificant level of MDA which dose not interfere with the active immunity following vaccination. So it is necessary to detect the MDA before vaccination to avoid vaccine failure and misuse of vaccine. This paper describes the influence of MDA to NDV vaccine for the optimization of vaccination schedule concerns to age of chicks originated from vaccinated and nonvaccinated parent stock.

\section{MATERIALS AND METHODS}

A locally produced Baby Chick Ranikhet Disease Vaccine (BCRDV) prepared from live lentogenic F-strain by the Department of Livestock Service (DLS) Dhaka and F-strain of NDV were used for this study during the period from July 2005 to May 2006. F-strain of NDV was collected from the repository of the Department of Microbiology and Hygiene, Bangladesh Agricultural University, Mymensingh and propagated in the virology laboratory of the same Department by inoculating embryonating chicken eggs of 9-10 days old through allantoic sac route using the procedure described by (Amin et al., 2004).

A total of 30 eggs from nonvaccinatid parent stock were incubated for 21 days to produce chicks which were used for the determination of MDA and detection of antibody level after vaccination. A total number of 40 dayold chicks of Cobb-100 breed with the history of vaccination of parent stock against ND were collected from Kazi Farms Ltd., Dhaka and carried to the experimental sheds of the Department of Microbiology and Hygiene, BAU, Mymensingh. The birds were reared and maintained with strict biosecurity.

In order to determine the persistence of MDA in chicks of vaccinated and nonvaccinated origin, these birds were grouped into group A and group B and each group containing 10 chicks. To determine the influence of MDA on vaccination against ND in chicks of vaccinated origin, the remaining 30 chicks were divided into 3 equal groups such as group C, group D and group E. To investigate the influence of MDA on vaccination in chicks of nonvaccinated origin the remaining 20 chicks were divided into 2 groups such as group $F$ and group $\mathrm{G}$. Each group was contained 10 chicks.

Blood samples were collected from five randomly selected chicks of groups A and B at 1, 3, 5, 7, 9, 11, 14, 18, 21, 24, 26, 29 and 34 days of age of chicks and subjected to hemagglutination inhibition (HI) test. Chicks of groups $\mathrm{C}$ and $\mathrm{D}$ were vaccinated with F-strain vaccine; BCRDV. Chicks of group $\mathrm{C}$ were vaccinated primarily at 4 days of age and booster dose was administered at 19 days of age. Chicks of group D were vaccinated singly without giving booster dose at 14 days of age, whereas group E was kept as control. From group C and D blood samples were collected after 7, 10 and 14 days of each vaccination. Blood samples were collected from group C at 3,11, 14, 18, 26, 29 and 34 days and from group D at 21, 24and 29 days age of chicks. Chicks of group F were vaccinated twice at 4 and 19 days of age with F-strain vaccine BCRDV and group $\mathrm{G}$ was kept as control. Blood samples were collected from group F before vaccination at day 3 and after 7, 10 and 14 days of each vaccination at day 11,14, 18, 26, 29 and 34 days and from group $G$ at $3,11,14,18,26,29$ and 34 days of age of chicks. All sera samples were then subjected to HI test.

\section{RESULTS AND DISCUSSION}

Persistence of MDA and its influence on development of immunity to BCRDV is determined and suggested an effective vaccination schedule in chicks of vaccinated and nonvaccinated origin shown in Table 1 and 2 . The existence of MDA was investigated by determination of HI titers starting from day 1 up to day 34. From Table 1 it was observed that chicks of vaccinated origin possessed high level of MDA of $8.00 \pm 0.71$ and the chicks of

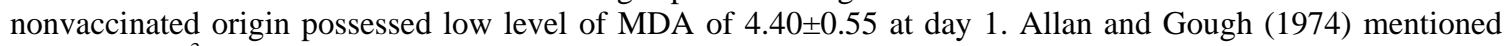
that $\mathrm{HI}$ titer $2^{3}$ gave protection to birds against ND if challenged with velogenic NDV. Accordingly the antibody titer remained at protective level till day 18 when the mean \pm SD of the $\log _{2}$ value of HI titer was $3.60 \pm 0.71$ in chicks of vaccinated origin. This result was correlated with the findings of Islam et al. (2003) who reported that the best MDA can be considered as an effective mean of protection of the chicken till two weeks of age. The mean \pm SD of $\log _{2}$ value of HI titer of $3.60 \pm 0.55$ was found in chicks of nonvaccinated origin at day 5. Negligible amount of antibody was measured in chicks of vaccinated origin from 24 days of age and the similar result was found in chicks of nonvaccinated origin from 11 days of age (Table 1). Saeed et al. (1988) reported that MDA decline to zero at day 25. 
Table 1. Comparison of persistence of maternally derived antibody (Mean \pm Standard deviation of $\log _{2}$ hemagglutination inhibition antibody titer) in chicks originated from vaccinated and nonvaccinated parent stock

\begin{tabular}{|c|c|c|c|c|c|c|c|c|c|c|c|c|c|}
\hline \multirow[t]{2}{*}{ Groups } & \multicolumn{13}{|c|}{ MDA $($ Mean \pm SD $)(n=5)$} \\
\hline & Day 1 & Day 3 & Day 5 & Day 7 & Day 9 & Day 11 & Day 14 & Day 18 & Day 21 & Day 24 & Day 26 & Day 29 & Day 34 \\
\hline \multirow[t]{3}{*}{ A } & 8.00 & 7.80 & 7.20 & 6.60 & 5.80 & 5.40 & 4.20 & 3.60 & 2.40 & 2.20 & 2.20 & 2.00 & 1.60 \\
\hline & \pm & \pm & \pm & \pm & \pm & \pm & \pm & \pm & \pm & \pm & \pm & \pm & \pm \\
\hline & 0.71 & 0.45 & 0.84 & 0.55 & 0.84 & 0.55 & 0.71 & 0.71 & 0.45 & 0.45 & 0.55 & 0.55 & 0.55 \\
\hline \multirow[t]{3}{*}{ B } & 4.40 & 4.20 & 3.60 & 2.80 & 2.40 & 2.20 & 2.00 & 1.80 & 1.60 & 1.40 & 1.40 & 1.20 & 1.20 \\
\hline & \pm & & & \pm & & \pm & \pm & \pm & \pm & \pm & \pm & \pm & \pm \\
\hline & 0.55 & 0.48 & 0.55 & 0.45 & 0.71 & 0.45 & 0.55 & 0.55 & 0.55 & 0.55 & 0.55 & 0.71 & 0.71 \\
\hline
\end{tabular}

$\mathrm{n}$ = Number of sera samples tested, Chicks of groups A and B originated from vaccinated and nonvaccinated parent stock respectively.

Table 2. Influence of maternally derived antibody on immunity level (Mean \pm Standard deviation of $\log _{2}$ value of hemagglutination inhibition titer) after vaccine administration following different vaccination schedule in chicks of vaccinated and nonvaccinated origin

\begin{tabular}{|llllllllll|}
\hline \multicolumn{2}{|c|}{ Groups } & HI antibody titers (Mean \pm SD) $(\mathrm{n}=5)$ & & & & & \\
\cline { 2 - 9 } & Day 3 & Day 11 & Day 14 & Day 18 & Day 21 & Day 24 & Day 26 & Day 29 & Day 34 \\
\hline C & $7.60 \pm 0.55$ & $5.80 \pm 0.84$ & $5.20 \pm 0.84$ & $4.60 \pm 0.89$ & ND & ND & $6.00 \pm 0.55$ & $6.80 \pm 0.48$ & $7.00 \pm 0.71$ \\
D & ND & ND & ND & ND & $5.80 \pm 0.71$ & $6.40 \pm 0.89$ & ND & $7.40 \pm 0.55$ & ND \\
E & $7.80 \pm 0.45$ & $5.20 \pm 0.45$ & $4.20 \pm 0.71$ & $3.60 \pm 0.55$ & $2.40 \pm 0.55$ & $2.20 \pm 0.45$ & $2.20 \pm 0.45$ & $1.80 \pm 0.45$ & $1.60 \pm 0.45$ \\
F & $4.20 \pm 0.45$ & $8.20 \pm 0.55$ & $8.60 \pm 0.55$ & $9.20 \pm 0.84$ & ND & ND & $9.60 \pm 0.55$ & $10.20 \pm 0.45$ & $11.20 \pm 1.00$ \\
G & $4.20 \pm 0.45$ & $4.20 \pm 0.45$ & $2.00 \pm 0.55$ & $1.80 \pm 0.45$ & ND & ND & $1.20 \pm 0.45$ & $1.20 \pm 0.71$ & $1.00 \pm 0.84$ \\
\hline
\end{tabular}

$\mathrm{ND}=$ Not done, $\mathrm{n}=$ Number of sera sample tested, Primary vaccination in group $\mathrm{C}$ and $\mathrm{F}$ at day 4 , Booster vaccination in group $\mathrm{C}$ and $\mathrm{F}$ at day 19 and Single vaccination in group D at day 14.

Table 2 represents the influence of MDA on immunity to BCRDV administration following different vaccination schedule in chicks of vaccinated and nonvaccinated origin. It is revealed that chicks of vaccinated origin possessed a high level of MDA titer of $7.80 \pm 0.45$ measured on 3 days after hatch in control group, group E which was similar to $\log _{2}$ value of HI titer of chicks of group C vaccinated with F-strain (7.60 \pm 0.55$)$ while the chicks of nonvaccinated origin possessed a MDA titer of $4.20 \pm 0.55$ measured on 3 days after hatch in group G which was also similar to $\log _{2}$ value of $\mathrm{HI}$ titer of chicks of group F vaccinated with F-strain $(4.20 \pm 0.45)$ (Table 2 ). It has been observed that the mean $\pm S D$ of $\log _{2}$ value of $\mathrm{HI}$ titer in chicks of group $\mathrm{C}$ of vaccinated origin were $5.80 \pm 0.845 .20 \pm 0.84$ and $4.60 \pm 0.89$ and the titer in chicks of group $\mathrm{F}$ of nonvaccinated origin were $8.20 \pm 0.558 .60 \pm 0.55$ and $9.20 \pm 0.84$ after 7,10 and 14 days of primary vaccination (Table 2). From Table 2 it is evident that in chicks of vaccinated origin 7 days after primary vaccination immunity level declined gradually may be due to the interference of MDA during vaccination but in chicks of nonvaccinated origin the immunity level gradually increasing as there was insignificant level of MDA during vaccination. It may be due to the presence of MDA. It was found that birds with protective MDA at the age of primary vaccination did not show any impetuous production of $\mathrm{HI}$ antibody such an observation is correlated with that of Eidson et al. (1976). They demonstrated that vaccination of chicks possessing high level of antibody produces minimal antibody responses and chicks possessing low level of antibody produces satisfactory antibody response. Biswas and Islam (2004) reported that the mean HI titer \pm Standard Error was $102.4 \pm 15.67$ in indigenous breeds having MDA titer of $<4$ at the time of vaccination and the mean HI titer \pm Standard Error was $32.0 \pm 8.76$ in Starbro 
breed having MDA titer of 16 at the time of vaccination. Paulillo et al. (1987) demonstrated that the immune response is improved in older chicks as level of maternal antibody fall and immunological maturity develops. From Table 2 it has been shown that after booster vaccination at 19 days of age the $\log _{2}$ value of HI titer were higher in all chicks those were vaccinated twice may be due to the low level of MDA at the time of booster vaccination. The mean \pm SD of $\log _{2}$ value of HI titer in chicks of group $C$ of vaccinated origin were $6.00 \pm 0.55$, $6.80 \pm 0.45$ and $7.00 \pm 0.71$ and the titer in chicks of group $F$ of nonvaccinated origin were $9.60 \pm 0.55,10.20 \pm 0.45$ and $11.20 \pm 1.00$ after 7,10 and 14 days of secondary vaccination (Table 2).

High titer of antibody after vaccination were also found in chicks of group D of vaccinated origin which were vaccinated once at 14 days of age when there was low level of MDA such as $4.20 \pm 0.71$ found in control group, group E. The mean \pm SD of $\log _{2}$ value of HI antibody titers were $5.80 \pm 0.71,6.40 \pm 0.89$ and $7.40 \pm 0.55$ after 7,10 and 14 days of vaccination. In this case there was no gradual declination of immunity level as MDA did not interfere with the development of active immunity This result directly supports the finding of Yamada et al. (1969). The authors suggested that chicks with congenital passive immunity to NDV showed no antibody response to intranasal $(\mathrm{i} / \mathrm{n})$ vaccination with $\mathrm{B}_{1}$ strain at 3-4 days of age, but vaccination at 12 days of age or later increased the protection against challenge to 80 percent or higher and vaccinated at 15 days of age increased antibody titers slightly. Gangopadhyay and Mallick (1971) demonstrated that the serological responses of chicks hatched from immune hens were generally poor when vaccinated in the first five days of life. However, in case of birds vaccinated at 10 days of age or later, the responses were better and immunity also set in about the $7^{\text {th }}$ day after vaccination.

Results of the present study recommends that for the control of outbreaks of ND in chickens and to prevent misuse of vaccine vaccination of chicks possessing high level of MDA might be vaccinated at 14 to 18 days of age once without giving booster dose and chicks possessing low level of MDA might be vaccinated twice at 4 and 19 days of age.

\section{REFERENCES}

1. Allan WH and Gough RE (1974). A standard haemagglutination inhibition test for Newcastle disease (2) Vaccination and challenge. Veterinary Record 95: 147-149.

2. Allan WH, Lancaster JE and Toth B (1978a). Newcastle diseases vaccines, their production and use. Chapter 3. Selection of the vaccine seed strain, FAO, Rome. p. 10.

3. Allan WH, Lancaster JE and Toth B (1978b). Newcastle diseases vaccines, their production and use. Chapter 11. Vaccination programmes. FAO, Rome. p. 93.

4. Amin MA, Amin MM, Khan MSR, Choudhury KA, Siddiky MNA and Sarker AJ (2004). Characterization of Newcastle diseases virus isolates form caged birds in Bangladesh. Bangladesh Journal of Veterinary Medicine 2: 113-116.

5. Biswas PK and Islam MA (2004). Humoral imune response of three vaccines prepared with three Lentogenic strains of Newcastle disease virus. The Bangladesh Veterinarian 21: 88-91

6. Chowdhury SI, Chowdhury TIMFR, Sarker AJ, Amin MM and Hossain WIMA (1982). Studies on Newcastle disease in Bangladesh. A research report. 2. The role of residual maternal antibody on immune response and selection of an optimum age for primary vaccination of chicks. pp. 12-22.

7. Eidson CS, Kleven SH and Villagas P (1976). Efficacy of intratracheal administration of Newcastle disease vaccine in day old chicks. Poultry Science 55: 1252-1257.

8. Gangopadhyay PK and Mallick BB (1971). Studies on Newcastle (Ranikhet) disease. II. Immunity developed after vaccination with ' $F$ ' strain of chicks hatched from eggs of immunized hens. Indian Veterinary Journal 48: 6-12.

9. Garib AISO, Gielkens ALJ, Gruys E and Koch G (2003). Review of Newcastle disease virus with particular references to immunity and vaccination. World's Poultry Science Journal 59: 185-198.

10. Islam MR, Huque QME, Giasuddin M, Alam J and Rahman MM (2003). Assessment of maternally derived antibody of commercial flock against Newcastle disease. Proceeding of $3^{\text {rd }}$ International Poultry Show and Seminar, Bangladesh China Friendship Conference Center, Dhaka, Bangladesh, $28^{\text {th }}$ February- $2^{\text {nd }}$ March 2003.

11. Keeble SA and Wade JA (1963). Inactivated Newcastle disease vaccine. Journal of Comparative Pathology and Therapy 73: 186.

12. Paulillo AC, Pinto AA, Berchieri Jr A, Ariki J, Salcedo PO and Quintana JL (1987). Newcastle disease: Immune response to live vaccine (La Sota strain) and inactivated vaccine (oil based) in broiler chicks carrying maternal antibodies. Australian Veterinary Journal 3: 235-242.

13. Saeed Z, Ahmad S, Rizvi AR and Ajmal M (1988). Role of maternal antibody in determination of an effective Newcastle disease vaccination programme. Pakistan Journal of Veterinary Research 1: 18-21.

14. Yamada S, Fujikawa H, Koda Y, Ichihara T and Ichihara T (1969). Immunization studies on Newcastle disease virus B1 strain. II. Immune response of chickens with congenital passive immunity. Journal of Japanese Veterinary Medical Association 22: 31-36. 